\title{
Pergunte de mais de uma maneira: alternativas para aumentar a eficácia da anamnese
}

\author{
Ask in more than one way: alternatives for \\ improving the patient history
}

\author{
PALAVRAS-CHAVE \\ - Relações médico-paciente \\ - Métodos \\ - Anamnese \\ - Comunicação \\ - Princípio cooperativo de Grice
}

Sebastião Josué Votre ${ }^{\mathrm{I}}$

Maria Carlota Rosa ${ }^{\mathrm{II}}$

Lucia Helena Alvares Salis ${ }^{I I}$

Diana Maul de Carvalho ${ }^{\text {II }}$

Nelson Albuquerque de Souza e Silva ${ }^{\text {II }}$

\begin{abstract}
R E S U M O
Este trabalho focaliza a comunicação na relação médico-paciente, identificando pontos potencialmente geradores de dificuldades linguísticas para o médico. Os aspectos focalizados dizem respeito, primeiramente, ao emprego, pelas partes envolvidas numa situação de comunicação, de variedades linguísticas diferentes; e em segundo lugar, às estratégias discursivas empregadas. Defendemos que, para o médico, é fundamental ter certeza de que compreendeu o problema que lhe foi trazido, mas, para isso, terá de procurar confirmar com o paciente, em diferentes momentos da consulta, sua compreensão das informações que está recebendo e saber passar-lhe, de modo compreensível, seu julgamento da situação clínica e as ações necessárias. As situações que ilustram os problemas aqui referidos fazem parte da experiência profissional dos autores.
\end{abstract}

\section{A B S T R A C T}

This article discusses communication in the physician-patient relationship with the aim of identifying potential instances of linguistic obstacles for the physician. The use of different linguistic variants and discursive strategies by the parties involved in communication are highlighted. The article shows that it is essential for physicians to be certain that they understand the problem brought by the patient or family, but this requires attempts to confirm this understanding at different moments during the interview, plus feedback on the physician's appraisal of the clinical situation and recommended measures. Situations illustrating the text are taken from the authors' own professional experience. 


\section{INTRODUÇÃO}

Este trabalho tem por objetivo servir de texto introdutório na formação médica, no tocante à interação linguística necessária no atendimento de saúde. Por essa razão, procuramos identificar aspectos potenciais de incompreensão nas trocas linguísticas entre médico e paciente. $\mathrm{O}$ foco do texto está no médico e em aspectos que poderiam causar insucesso em sua busca de organização da informação. Procuramos chamar a atenção para o fato de que a anamnese, importante e complexa técnica que o médico utiliza para tomar decisões em benefício do paciente, exige conhecimentos de áreas diversas, como neurociências, linguística (enquanto neurociência e enquanto ciência social), literatura, clínica, filosofia, computação e comunicação. Essas áreas precisam se interconectar para podermos avançar nesse complexo domínio.

A prática clínica caracteriza-se, essencialmente, na relação entre o profissional médico e o paciente, sem ignorar que outros atores, como os familiares, podem facilitar ou dificultar essa relação. Essa interação deve ocorrer em ambiente de confiança mútua e de compreensão entre aquele que procura auxílio e o profissional capacitado para prover esse auxílio, para que seja favorecida a boa aplicação do método clínico no qual o médico se baseia para tomar decisões. O médico colhe o maior número possível de informações relevantes sobre o doente e sua doença, interpreta essas informações, raciocina, sempre num contexto de incerteza, com base epidemiológica e fisiopatológica, e decide sobre o diagnóstico mais provável, por vezes com o auxílio de exames complementares. Decide então se apenas observa a evolução do paciente ou escolhe a intervenção mais adequada em função do prognóstico mais favorável (sem ou com intervenção). Portanto, as ações médicas fundamentais visam ao estabelecimento do diagnóstico, do prognóstico e da terapêutica ${ }^{1}$.

Para a eficácia dessas ações, a interação médico-paciente é de importância primordial. Só por meio dela o médico pode caracterizar o estado transiente de evolução do indivíduo, definindo esse estado segundo padrões reconhecidos como saúde ou doença. Tais padrões são estabelecidos por intermédio dos símbolos emitidos pelo paciente, identificados por meio da linguagem e da observação. Esse estado transiente e evolutivo da vida é função do genoma único dessa pessoa e da constante interação desta com o ambiente, incluindo os aspectos socioculturais.

Durante o encontro inicial médico-paciente, ambos sofrem influências recíprocas e buscam estabelecer um padrão de comunicação que permita a evolução comum do entendimento do processo saúde-doença. Fatos recentes e do passado influenciam este processo, e a informação obtida na anamnese pode fornecer dados e permitir o reconhecimento dos símbolos que configuram determinado padrão e caracterizam os estados evolutivos desse processo. Assim, conhecendo a evolução da vida do paciente e seu estado atual, poderemos elaborar previsões sobre o comportamento futuro desse sistema complexo, de modo a intervir de modo benéfico naqueles casos que possam ser auxiliados pelas intervenções terapêuticas para recuperação ou manutenção do estado de saúde.

Os avanços no conhecimento do funcionamento cerebral, trazidos pelas neurociências, têm permitido compreender que o processo de interação organismo/ambiente ocorre em todos os órgãos de cada indivíduo, incluindo o cérebro, e durante toda a vida. Assim, todos os tecidos parecem ser dotados de plasticidade, ou propriedade de se modificar e de se reorganizar constantemente. Cada ser humano (e seu cérebro) é único e, para que possa entender outros, há necessidade da compreensão dos variados símbolos emitidos por cada um, mesmo que falem a mesma língua. Na construção desse processo de comunicação todos se modificam ${ }^{2,3}$.

Parte das dificuldades do julgamento clínico decorre da interação inicial e sequencial com os pacientes. Este trabalho, marcado pela orientação pragmática, tem como objetivo contribuir para a compreensão dos fatores envolvidos no processo comunicativo e analisar a relação entre médicos e pacientes. A hipótese acolhida é que as falhas decorrem em parte das representações que os médicos têm de si mesmos e dos pacientes, como cidadãos ${ }^{4}$. Na análise do discurso médico, identificamos e descrevemos os percalços mais comuns na comunicação. A partir da reformulação do princípio cooperativo de Grice ${ }^{5}$, em nova contextualização ética e pedagógica, propomos estratégias para o aprimoramento da arte de perguntar e interpretar, com vistas ao alcance de metas específicas e alternativas de treinamento para os trabalhos linguísticos de interação entre médico e paciente ${ }^{6,7}$.

Nas seções que se seguem apresenta-se uma visão geral sobre a compreensão da linguagem. Em seguida, discute-se a questão da variabilidade linguística, ou seja, como as variedades regionais, sociais e profissionais de uma língua fazem com que, muitas vezes, surjam problemas na interação. Discutem-se exemplos selecionados a partir da experiência dos autores e, nos dois últimos segmentos, discute-se o papel do médico nesta interação e são encaminhadas sugestões para a superação de impasses comunicativos.

\section{COMPREENDENDO O QUE É DITO}

Logo após o nascimento, tem início um processo cognitivo complexo que levará o indivíduo ao domínio de uma língua (ou línguas). Essa língua será aqui designada língua materna; o conjunto de enunciados dessa língua que o indivíduo ouvirá no convívio com os que o cercam será aqui designado experiência linguística.

Com base na experiência linguística a que é exposto na infância, cada indivíduo constrói seu conhecimento da língua materna, isto é, sua gramática, o conhecimento que lhe permitirá falar e 
entender um número infinito de frases que não fazem parte de sua experiência linguística prévia. No sentido em que aqui se emprega o termo gramática, todos os falantes dominam uma gramática, independentemente do nível de escolaridade.

Uma vez que cada indivíduo constrói sua gramática, as gramáticas variam, mesmo que se leve em conta apenas o núcleo familiar. Em geral, essas diferenças não recebem a atenção dos falantes ou sequer são compreendidas como diferenças no conhecimento linguístico. Eis um exemplo: os pais de um dos autores deste texto, oriundos do interior de Portugal, corrigiam-no quando criança com relação ao emprego da forma MORTO, para eles apenas particípio/adjetivo relacionado a MORRER, mas não a MATAR. Assim, para os pais, seria legítimo empregar Ele está morto para falar de alguém que morresse em decorrência de uma doença, por exemplo, mas jamais para alguém assassinado. A correção, caso a criança empregasse MORTO para MATAR, vinha sempre sob a forma Então não está morto; mataram-no. O diálogo que se seguia invariavelmente (Se mataram ou se morreu não está morto? - ao que os pais retrucavam com um solene não) demonstrava como nenhuma das partes compreendia que ambos estavam diante de usos distintos: para os pais, a criança falava errado, e eles procuravam corrigi-la; para a criança, aquilo não era entendido como uma correção, mas como uma resposta absurda.

Uma expressão como a gramática do português é, portanto, uma forma de generalizar a referência às gramáticas dos falantes de português. Não há duas crianças que compartilhem os mesmos dados linguísticos primários; elas ouvem coisas diferentes. A despeito da variação na experiência, as gramáticas resultantes dessa construção individual são semelhantes, o que torna possível a intercomunicação ${ }^{3,8}$. Construída a gramática, será possível ao indivíduo produzir (e também compreender) um número infinito de frases, bem como parafrasear outros enunciados, identificar ambiguidades e distinguir possibilidades e impossibilidades em sua língua.

A experiência linguística a que uma criança está exposta, além de variada, é composta por evidências esparsas ${ }^{3}$. Os dados não recebem marcas especiais, sejam fragmentos de frases ou até mesmo construções malformadas; apesar disso, nenhuma criança generaliza tais casos. Essa questão, referida como pobreza do estímulo, é tomada como evidência a favor de se postular um mecanismo mental inato na aquisição linguística. Os estudos sobre um tipo especial de fala dirigido a crianças para que elas entendam melhor os adultos, em geral referido como maternalês ou manhês (do inglês motherese), não evidenciam qualquer correlação entre, de um lado, o uso de estruturas simples ou de estruturas complexas pelo adulto e, do outro, o domínio de apenas um dos tipos pela criança ${ }^{9}$.
A construção individual de uma língua na mente/cérebro do falante não nega a inter-relação com o meio. Não se nega que em parte uma língua é aprendida, porque a criança não desenvolve uma língua se for isolada do contato linguístico. Além disso, a criança fala a(s) língua(s) que faz(em) parte de sua experiência linguística, e não qualquer das outras cerca de 6 mil línguas ainda faladas no mundo ${ }^{10}$.

\section{Detectando e distinguindo os sons da fala}

Em termos gerais, a compreensão da fala é uma tarefa complexa. Dentre os muitos ruídos, temos de detectar e distinguir aqueles que são linguísticos. Nosso preparo para essa tarefa é impressionante: percebemos cerca de dez fones por segundo na fala normal de uma língua em que temos fluência ${ }^{11}$, podendo mesmo chegar a 50 ou 60 fones por segundo ${ }^{4,11}$. E é bom que assim seja, porque, com velocidade normal, enunciamos cerca de seis sílabas por segundo ${ }^{12}$. Mesmo quando outros ruídos interferem no sinal acústico, conseguimos lançar mão de estratégias que levam a compreender o que deve ter sido dito.

Sternberg ${ }^{4}$ e Eysenck \& Keane ${ }^{11}$ relatam um experimento em que a frase It was found that the *eel was on the... era dita aos participantes do teste, e escolhida a última palavra entre as alternativas axle (eixo), shoe (sapato), table (mesa) ou orange (laranja). Na posição assinalada com o asterisco, no lugar de uma consoante era inserido um ruído não linguístico (tosse, por exemplo), de modo que a consoante não era pronunciada. Os participantes, por conseguinte, não podiam ouvir a consoante inicial, porque ela não era dita, mas quase nenhum se lembrava de ter ouvido o ruído. Em face da solicitação para dizerem o que tinham ouvido, os participantes recompunham a frase, ajudados pelo contexto, e afirmavam ter ouvido uma das frases seguintes:

- The wheel was on the axle (a roda estava no eixo)

- The heel was on the shoe (o salto estava no sapato)

- The meal was on the table (a refeição estava na mesa)

- The peel was on the orange (a casca estava na laranja)

Dificilmente dizemos palavras em isolado, mas as entendemos, apesar de serem enunciadas num contínuo sonoro. Na fala espontânea, os silêncios nos enunciados ocorrem preferencialmente não a cada fronteira entre palavras, mas nas fronteiras que coincidem com fronteiras entre unidades sintáticas e antes das categorias lexicais maiores ${ }^{12}$. Além disso, uma série de processos fonéticos ajuda a esconder as fronteiras entre palavras. Na fala espontânea, uma frase como as abelhas africanas, por exemplo, é ressilabificada em a.za.be.lha.za.fri.ca.nas, mas, mesmo assim, percebemos as três palavras ali contidas. Apesar de enunciarmos contínuos sonoros, contamos com fatores que nos ajudam a 
reconhecer as palavras num enunciado, e nessa tarefa nos saímos bem. Assim, caso o médico não tenha problemas de audição, a percepção do sinal acústico da fala do paciente e a segmentação desse sinal em unidades de som e significado não serão a fonte de problemas entre ele e o paciente.

Reconhecer o sinal acústico é parte do conhecimento de uma palavra. Para conhecer uma palavra, é necessário não só dominar a relação existente entre uma cadeia sonora e seus significados, mas também: (a) poder atribuir uma classe gramatical a essa unidade de som e significado, o que permite distinguir sequências semelhantes (Como foi o jantar? / No jantar eu nunca como muito) que não são a mesma palavra; e (b) conhecer as propriedades que permitem empregar apropriadamente as palavras que têm mais de uma forma (eu como, mas não eu comes).

Conhecer o vocabulário da língua não impede que, na fala espontânea, possam ocorrer erros momentâneos, decorrentes da similaridade sonora, da similaridade existente entre os significados de palavras distintas, ou de ambas. Ou ainda quanto à colocação dos elementos. Esse tipo de erro é comumente referido como lapsus linguae. Aitchison ${ }^{12}$ aponta que esse tipo de erro segue padrões previsíveis. Eis alguns exemplos do primeiro tipo: energia/alergia (solicitado a passar inseticida em coqueiros, um empregado diz ao patrão que não pode fazer isso porque tem energia); alimentação/ornamentação (um agricultor diz que a murta serve para alimentação em Campina Grande, onde os artesãos trabalham com ela); periscópio/estetoscópio (uma senhora observa que estudantes de Medicina adoram andar com o periscópio no pescoço).

Eis um exemplo do segundo tipo: a repórter de televisão, em face de uma onda de frio, comenta que as pessoas tiraram do armário gorros, luvas e cacharéis (por cachecóis). Um exemplo do terceiro tipo: presos depedram presídio (por depredam).

Os lapsos podem afetar a ordem das palavras. Numa entrevista na rádio CBN (por Heródoto Barbeiro em 20-06-2008), perguntou-se ao entrevistado quanto de sangue podia então haver no álcool, em lugar de quanto de álcool passava a ser aceito no exame de sangue de um motorista.

Nem sempre o erro de seleção é uma confusão momentânea. O falante pode desconhecer a forma corrente e confundir regularmente termos em que percebe alguma semelhança fônica. Este pode ser um fator de incompreensão caso o contexto não seja suficiente para levar a perceber que há algo estranho.

Conseguir segmentar o enunciado em palavras não é condição suficiente para evitar problemas na comunicação. Para entender uma frase é necessário mais do que somar os significados dos termos que a compõem: é preciso perceber que as palavras fazem parte de uma organização estrutural complexa. Essa estrutura é a sintaxe da língua, que seus falantes conhecem a ponto de poderem, sem dificuldades, interpretar frases como as seguintes:

a. Nesta terra de hábitos estranhos, as pessoas lavam-se apenas uma vez por mês.

Nesta terra de hábitos estranhos, lavam-se as pessoas apenas uma vez por mês. [adaptado de Grice ${ }^{5}$ ]

b. O presidente está em casa.

O presidente está na casa. [adaptado de Grice ${ }^{5}$ ]

c. O cachorro que perseguiu o gato matou o rato.

d. Ele voou para São Paulo, e a sócia, para João Pessoa.

e. Como foi que você achou o cadáver? - Morto. [adaptado de Raposo ${ }^{6}$ ]

As frases em (a) diferem na medida em que não têm o mesmo sujeito para lavar. A diferença entre as frases no par em (b), em casa versus na casa, se deve a um elemento da estrutura gramatical, o artigo $a$. É difícil tentar explicar a alguém qual o significado de um artigo, porque não se trata de um significado que faça referência a um ser, ação ou qualidade. A presença de artigo (na casa versus em casa) leva a interpretar que a casa de que se fala não será, necessariamente, a do presidente. A frase em (c) ilustra a interpretação de relativos, como que, compreendidos prontamente por um falante de português. Em (d), não há nada que diga explicitamente que a sócia seguiu para João Pessoa de avião; no entanto, ninguém que ouvisse essa frase perguntaria se a sócia viajou dirigindo o próprio carro. Em (e), as coisas se complicam: a pergunta poderia dizer respeito à posição em que o corpo foi encontrado, ou ao modo como se chegara à localização do cadáver (uma denúncia? o acaso?), ou dizer respeito aos fenômenos que ajudariam a detectar o tempo transcorrido desde a morte, ou ser uma indagação sobre o tipo de lesões que o corpo apresentava. A informação pretendida por quem pergunta, num contexto em que já se sabe que há um corpo, certamente não seria a escolhida na resposta em (e); tal resposta só seria possível se a pergunta fizesse menção não a um cadáver, mas a uma vítima, por exemplo.

A interpretação da frase (c) parece trivial. Entretanto, as estruturas encaixadas podem ser intransponíveis em casos de falante que apresente agramatismo ${ }^{13}$.

A construção individual do conhecimento linguístico é fonte de variação entre falantes pertencentes ao mesmo grupo social. Essa variação pode ser tão pouco percebida para os falantes quanto a possibilidade de o acento secundário recair na primeira ou na segunda sílaba de uma palavra se o número de sílabas pretônicas for ímpar ${ }^{14}$, como nos exemplos a seguir, em que a sílaba tônica foi assinalada com sublinhado, e o acento secundário, com itálico: a.ba.ca.xi/a.ba.ca.xi; a.pren.di.za.gem/a.pren.di.za.gem.

Assim, numa comunidade linguística, apesar da semelhança nos usos linguísticos de seus integrantes, há variação, isto é, dife- 
rentes expressões linguísticas de um mesmo fenômeno. Mesmo quando médico e paciente pertencem à mesma comunidade linguística, conhecer as palavras e aplicar-lhes um lugar numa estrutura sintática não são garantia de que queixas como "tenho uma cachoeira no peito", " quando acabo a natação sinto como se tivesse agulhas nos dedos da mão direita", "sinto coceira no coração" serão fáceis de interpretar. A variação é maior se levarmos em conta falantes com diferentes origens, sociais ou regionais. Esta é a situação comum no atendimento médico, em especial numa grande cidade como o Rio de Janeiro.

\section{VARIABILIDADE LINGUÍSTICA}

Em decorrência da construção individual da gramática, avulta o problema da variabilidade, sendo impossível conhecer a língua toda, isto é, todas as palavras em uso em todas as regiões em que se fala português, por todos os grupos profissionais e sociais, mais as regras que permitem todas as construções sintáticas de todos esses grupos e lugares. As variedades regionais, sociais e profissionais de uma língua fazem com que, muitas vezes, surjam problemas na interação. Focalizamos a seguir duas situações de variação que podem gerar problemas de comunicação: (a) diferenças linguísticas entre falantes de origens geográficas distintas; (b) o jargão profissional.

\section{Diferenças decorrentes da região de onde vêm os falantes}

Quem vive boa parte de sua vida numa dada região incorpora marcas linguísticas que identificarão sua procedência - seu dialeto regional, um conjunto de traços linguísticos que identifica a região de origem do falante. Os dialetos regionais podem ter ou não prestígio social, quadro que pode se alterar com o tempo, como no caso do dialeto carioca. Ramos ${ }^{15}$ demonstrou que, em 20 anos, a aceitação do dialeto carioca como modelo para os demais falantes do País baixou de $19,9 \%$ para $8,5 \%$. Segundo a pesquisa, para os mineiros de Belo Horizonte, o dialeto mais próximo ao padrão seria o dialeto paulistano, e o dialeto carioca, o mais distante desse padrão. O jornalista Sidney Rezende (comunicação pessoal), apresentador de noticiário local na mesma rede, confirma os dados de $\operatorname{Ramos}^{15}$ : a fala carioca pode ser aceita no $R J-T V$, mas, se empregada em rede nacional, poderia implicar aumento na dificuldade de compreensão da notícia para quem não é da região. Estariam nesse caso dados encontrados em. Ferreira ${ }^{16}$, referentes ao interior de Sergipe, que apontam o apagamento de material fônico em palavras que, em outras regiões, são proparoxítonas: cavica e cavicla, por clavícula; ócus por óculos ou ainda veronca por verônica (medalha).
A pronúncia não é, porém, a única marca que diferencia falantes de regiões distintas, e a dificuldade resultante de usos desconhecidos de uma palavra ou de palavras desconhecidas pode ser mais difícil de contornar. Os exemplos a seguir apresentam usos desconhecidos para um carioca: (a) Justamente, quando a muther perde os tempo, a gente falamo que ela amarrou o facão, não é? ${ }^{16}$ (carta 92n); (b) Vilide, uma pinta branca que sai no preto do olho ${ }^{17}$ (carta 94n). A expressão perder os tempo equivale a "entrar na menopausa", sem relação com perder tempo; e a substituição por "amarrar o facão" não chega a ajudar. Vilide, sinônimo de catara$t a$, não tem uso no Rio de Janeiro. Nos dois casos o ouvinte percebe que algo lhe foge à compreensão e poderá pedir explicações para elucidar suas dúvidas.

O problema é mais difícil de detectar, e nos preocupa neste artigo, quando os interlocutores não percebem que falam de coisas distintas, com a mesma denominação. No Rio de Janeiro, mosquito designa insetos de diferentes espécies, mas nunca aqueles designados pelo termo mosca. Assim, uma casa cheia de mosquitos pode significar coisas diferentes para um carioca e para um paraibano, por exemplo, sem que percebam que não falam exatamente da mesma coisa. Uma situação desse tipo ocorreu durante um inquérito de saúde realizado em povoados do sudeste do Piauí nos anos 1990. O questionário continha a pergunta Você já foi picado por escorpiões? A área tinha muitos relatos desse tipo de acidente, mas os entrevistados responderam que nunca haviam sido picados por um escorpião, mas que já haviam sido picados por um outro animal venenoso, a lacraia. A dúvida quanto à interpretação das respostas só foi dirimida com a apresentação de dois desenhos aos participantes do inquérito, um que reproduzia uma lacraia, e o outro, um escorpião. O dialeto dos pesquisadores denominava escorpião o que o dos pesquisados denominava lacraia.

Na segunda metade do século 20, no Rio de Janeiro, a pergunta Você conhece o barbeiro? era comumente feita pelos médicos a pacientes vindos de áreas endêmicas da doença de Chagas. Hoje, o vetor doméstico assim denominado está erradicado na antiga área endêmica, e a migração diminuiu consideravelmente. Assim, essa é atualmente uma pergunta que pode soar inusitada, vinda de um médico que levanta dados sobre a vida de seu paciente.

\section{Jargões profissionais e vocabulários sociais}

As profissões contam com léxicos específicos, que facilitam a comunicação entre pares. No caso da medicina ocidental, as iniciativas para prover a área de terminologia unificada, evitando diferentes nomes para a mesma doença, tiveram início há alguns séculos. Na segunda metade do século 19, os Congressos Inter- 
nacionais de Estatística - o primeiro ocorreu em 1853 em Bruxelas - discutiram propostas de classificação de causas de morte que viabilizassem estudos comparativos de mortalidade. Finalmente, o Instituto Internacional de Estatística (sucessor do Congresso Internacional de Estatística), em sua reunião de 1893, aprovou uma Classificação Internacional de Causas de Morte (a Classificação Bertillon) que foi adotada por muitos países e é considerada a precursora da Classificação Internacional de Doenças atualmente em uso por todos os países signatários da Carta da Organização Mundial da Saúde ${ }^{18}$.

A formação médica exige o domínio da terminologia padronizada, que difere, muitas vezes, da denominação não técnica. Pacientes podem não entender o que os médicos perguntam se a pergunta envolver termos como sudorese, diurese, rash... O valor informativo de uma resposta do paciente a perguntas incompreendidas é nulo. Nesse contexto, o uso de termos técnicos pelos profissionais da saúde pode resultar em problemas na comunicação com os pacientes. Mesmo quando o termo utilizado soa como o mesmo para ambos, isso pode não ser exatamente verdade. Se o paciente se queixa de febre, pode estar dizendo que sentiu o corpo quente ainda que o termômetro não registre aumento da temperatura, mas este último dado estará sempre presente na definição de febre pelo médico.

Por outro lado, estamos diante de uma situação delicada. A substituição de terminologia por vocabulário não técnico pode ser mal compreendida. O paciente pode sentir-se melindrado ao ouvir que a taxa de bolinhas (em lugar de plaquetas) no sangue está baixa por conta do dengue, mesmo que seu conhecimento sobre plaquetas derive da informação repetidamente veiculada na imprensa de que é perigoso quando baixam demais no organismo. Ou ainda: pode levar a desconfiar da própria qualidade da formação do médico.

\section{O LADO ÉTICO E DISCURSIVO DA INTERAÇÃO MÉDICO-PACIENTE}

A interação médico-paciente envolve mais do que a informação construída pelos sons, sintaxe e itens léxicos. A produção de diálogos eficazes repousa na ética da compreensão das características fundadoras dos discursos que essa pessoa produz e a que é exposta na sua vida cotidiana. Neste trabalho, entendemos o lado ético da interação comunicativa como respaldado na atitude do médico, de respeito à sua própria pessoa e à pessoa do paciente, como cidadãos responsáveis, com direitos linguísticos assegurados, que devem ser respeitados e cuidados. Entendemos também que cabe ao médico um tipo de cuidado específico em face da competência linguística do paciente. Compreendemos como discurso toda e qual- quer manifestação verbal, na forma de texto, oral ou escrito, a que se associam representações, valores, crenças e atitudes de seus usuários. A lista de discursos é infindável, e podemos começá-la com o discurso político, o religioso e o pedagógico, o discurso médico, o da educação médica.

O médico identifica (nomeia) uma doença a partir de um modelo que se traduz em um conjunto de sinais e sintomas dispostos em sequências temporais, medidos em sua intensidade, qualificados. O discurso do paciente está estruturado em termos das suas próprias relevâncias e não das relevâncias que o médico espera. Cabe, pois, ao médico orientar esforços e dirigir estratégias para identificar no discurso do paciente os indícios dos quadros que reconhece como uma doença. A expectativa é que a atitude do médico seja de confiança e respeito para com o paciente, de prontidão para a escuta, de humildade na busca do saber.

Um recurso excelente para o médico é a paráfrase produtiva: pergunte de mais de uma maneira, recorra a sinonímias, peça, de outro modo, que conte novamente, que explique com detalhes e sequencialmente a história relatada ou o desenvolvimento do sintoma, explore o estoque das alternativas: como, quando, onde, com que intensidade, com que frequência, por quê? Não se contente, por exemplo, com a resposta afirmativa à pergunta se o paciente sentia ou não cansaço. Não vá logo inferindo tratar-se de dispneia. O paciente pode estar se referindo a moleza, astenia. Mesmo se for falta de ar, procure entender se essa falta de ar se expressa como uma respiração superficial e acelerada (indicativa de dispneia cardíaca ou pulmonar) ou se o paciente descreve uma inspiração profunda (sugestiva de dispneia suspirosa, por ansiedade). Temos um exemplo sobre dor torácica. Perguntado se a dor no peito ocorria com esforço, o paciente respondeu que sim. A interpretação do médico foi tratar-se de um caso de angina pectoris por insuficiência coronariana. Perguntado de outra maneira, se a dor ocorria durante ou após o esforço, o paciente informou que a dor ocorria horas após o esforço. O paciente fazia uma relação entre o esforço ocorrido horas antes e a dor. No entanto, a dor durante o esforço tem interpretação clínica diferente da dor ocorrida pós-esforço. Ao ouvir um paciente que se queixa de tonteira, palavra que tem inúmeras conotações, o médico terá de buscar uma descrição detalhada sobre se tem ou não relação postural ou sensação de movimento (vertigem), ou sensação de escurecimento visual, com sensação de desmaio ou de cabeça oca, etc.

\section{O princípio cooperativo como guia na interação médico-paciente}

O filósofo da linguagem Paul Grice (1913-1988) ${ }^{5}$ propôs que um princípio cooperativo preside as conversações e que os falantes lançam mão desse princípio, de forma inconsciente, mas regular 
e sistemática, para garantir uma comunicação eficiente. O princípio se apresenta sob a forma de quatro máximas: quantidade, qualidade, relação e modo. A máxima da quantidade se apresenta nos seguintes termos: Faça sua contribuição tão informativa quanto for necessário (para os propósitos do intercâmbio). Não faça sua contribuição mais informativa do que se requer. A máxima da qualidade assim se formula: Procure construir uma contribuição verdadeira. Não diga o que você acredita ser falso. Não diga nada sem evidência adequada. A máxima da relação é mais sucinta: Seja relevante. Por fim, a máxima do modo se refere a como dizer, de modo a evitar obscuridade, ambiguidade e prolixidade.

Admitindo-se que Grice ${ }^{5}$ tem razão, perguntamos por que há impasses na comunicação entre médico e paciente ou, de forma geral, entre as pessoas. Segundo nossa percepção, é porque, no contexto aqui analisado, se trata de comunicação singular, em que ao médico, interessado no que o paciente diz sobre aspectos específicos de sua própria experiência de sofrimento e dor, cabe apenas perguntar. Frente a esse tipo especial de conversação, postulamos uma nova formulação para as máximas descritivo-prescritivas que o médico, como entrevistador, cumpre ou procura cumprir no curso da entrevista. Eis uma primeira versão dessas "novas" máximas, específicas da interação médico-paciente, com referência ao termo de Grice:

- Confiabilidade (qualidade): mostre ao paciente que acredita no que ele fala e que confia nele;

- Informatividade (quantidade): utilize paráfrases, retome as perguntas, pergunte de outra maneira, busque detalhes dos fatos ou sintomas relatados, procure ordená-los sequencialmente no tempo, até ter evidência confiável de que obteve informação suficiente;

- Clareza (modo): evite o jargão técnico, evite o epônimo, a ambiguidade e a prolixidade; faça sua comunicação o mais simples e clara possível;

- Atenção/respeitabilidade (relação): deixe o paciente falar, escute com atenção, não interrompa sua narrativa, "fique rouco de ouvir"; faça um "eco", isto é, repita a última sentença falada pelo paciente para induzi-lo a continuar a narrativa, se a havia interrompido; procure entender o que o paciente relata, adote atitude de respeito à pessoa.

\section{O papel do médico na cooperação}

Para a educação médica, a levarmos em conta as ideias de Coelho Filho ${ }^{19}$, Moral $^{1}$ e Rios ${ }^{20}$, a máxima da clareza merece um comentário à parte, pois a expectativa é que haja uma troca conversacional que leve à informação necessária para o médico identificar o pro- blema de saúde que fez o paciente procurá-lo. Identificar o problema de saúde significa aqui traduzir a fala do paciente (o problema, como definido por ele) para os termos que constroem um significado específico na linguagem do médico. Deste modo, o problema do paciente pode ser encaixado na classificação de doenças que o médico reconhece segundo sua teoria das doenças.

A expectativa é que ambos estejam interessados em contribuir para a eficiência da comunicação, o que implica que devem estar em atitude cooperativa. Não ser cooperativo, para cada um deles, significa não aceitar participar da situação comunicativa, o que poderia se manifestar de várias maneiras, como, por exemplo, da parte do paciente, dizer que não quer falar/responder, ficar em silêncio ou mesmo dar as costas e retirar-se. Da parte do médico, não prestar atenção ao que o paciente diz, interromper o paciente, impedir seu discurso, passar a escrever sem olhar para o paciente, entre outros indícios de fraca interação com ele. O médico pode achar que não precisa deste diálogo, pois dispõe hoje de uma sofisticada bateria de exames que vão mostrar o problema muito melhor do que qualquer coisa que o paciente diga. Essa crença de alguns médicos, e de alguns pacientes, construída sob influência do desenvolvimento tecnológico, do marketing de produtos e da mídia, não encontra suporte nos estudos que apontam que mais de $70 \%$ dos diagnósticos são feitos na anamnese.

Entre os vários fatores de insucesso na comunicação, da parte do médico, é crucial a escolha dos termos. Antes de ser um profissional da saúde, o médico é um ser humano construído na linguagem, é membro de uma comunidade discursiva e, na comunicação com o paciente, lida com a linguagem de um estrato social ou intelectual que lhe exige atenção e adequação no uso dos termos e expressões. O foco dos problemas linguísticos do médico está no domínio dos recursos para extrair o núcleo do tópico discursivo do paciente, manipular os subtópicos, concentrar a atenção nesse núcleo e fazer avançar a compreensão sobre o que o paciente diz, mediante perguntas éticas, claras, relevantes, sérias, responsáveis e comprometidas.

O sucesso ou insucesso da anamnese está relacionado, em parte, à atitude do médico em face da verdade dos fatos e sintomas que é construída pelo paciente. Cabe-lhe a postura segundo a qual a verdade do paciente existe. Essa verdade sairá da boca do paciente, desde que o médico seja cooperativo, atento, cuidadoso, direcionador. Especialmente se ele conseguir entender que está tentando traduzir de uma língua que, teoricamente, os dois falam (mesmo com todos os problemas aqui apontados) para uma outra que o paciente não fala - ainda que seja construída com os mesmos conjuntos de sons. Um dos problemas é que o médico, em geral, não percebe que passou os três primeiros anos 
da faculdade aprendendo uma nova língua (que muda o significado de palavras antigas e acrescenta um novo vocabulário) e não apenas novos termos da velha língua.

O modo de o médico obter as informações não está codificado numa fórmula, mas o referencial teórico aqui apresentado ancora a hipótese seguinte: há um espectro possível (identificável) de problemas do paciente que é, para o médico, predefinido. Pode ser uma série de perguntas diretas, cada uma delas aprofundando a anterior e acrescendo um detalhe que é relevante para a compreensão do problema do paciente. Uma pergunta direta pode assumir diferentes formulações e retomadas, identificadas por diferentes curvas prosódicas. Quem começa a falar normalmente é o paciente, mas quem deve conduzir as perguntas é o médico, que, nesse contexto, é quem tem o saber/autoridade/poder ${ }^{21}$. Ao paciente cabe respondê-las, até porque foi ele quem procurou o médico em busca de ajuda. E ele o fará tão mais adequadamente, quanto mais o médico criar contextos positivos, confiáveis, segundo preveem as máximas do princípio cooperativo, formuladas acima.

Ao lançar mão de perguntas diretas, o médico deve esperar respostas curtas. Afinal, cabe ao paciente ser informativo, claro e relevante ou, em outras palavras, dar uma resposta adequada, relacionada ao tópico focalizado na pergunta, falar daquilo que lhe foi perguntado e não de outras informações. Cabe ao médico avaliar o que o falante vai lançando no seu discurso e selecionar o que leva ao foco do que quer saber. Isto não implica interromper a fala do paciente e, sim, identificar, nessa fala, mesmo que aparentemente prolixa, os pontos fundamentais do discurso, que podem não estar em uma resposta direta ao que o médico perguntou, mas em palavras, frases ou narrativas aparentemente sem relação com a pergunta feita. Para isto, é fundamental a constante atenção ao que é dito pelo paciente.

Dizer apenas o necessário, nem mais, nem menos, pode ser variável, dependendo do contexto e da complexidade do tópico. Cabe ao médico, atento ao princípio da integralidade, procurar não se distrair, não perder ganchos preciosos, que o levariam ao âmago do problema. O outro lado da questão é que, para ser informativo e relevante, o paciente pode deixar de lado a informação que considera sem relevância, mas que é fundamental para os propósitos do médico. É comum o relato de médicos sobre pacientes que não mencionaram algo que lhes parecia trivial, como, por exemplo, uma dor de cabeça, e que era uma indicação relevante para o diagnóstico. Um paciente com hipertensão arterial pode não considerar relevante mencionar para o cardiologista um sintoma de dor epigástrica intermitente, por não perceber a importância de uma dor no estômago que sequer sente naquele momento para uma consulta cardiológica, especialmente se já havia procurado um gastroenterologista e já realizara uma endoscopia. Essa dor epigástrica, que é relevante, pois se trata de dor secundária à insuficiência coronariana, só será mencionada após extensa anamnese, com perguntas feitas de várias maneiras.

O princípio geral da cooperação diz respeito à adequação da informação veiculada ao seu contexto comunicacional. Há outra questão que não pode ser esquecida. Trata-se do cuidado em assegurar que o que se diz ou aquilo que se cala não constrange o outro. O termo polidez é empregado em linguística para denominar o cuidado com "o efeito do que dizemos sobre as outras pes$\operatorname{soas}^{\prime 22}$ (p. 18). Vivemos um tempo de atenção às diferenças, de foco na cidadania conquistada e reclamada, em que a polidez passa a ser interpretada como moeda forte.

\section{CONSTATAÇÕES E ENCAMINHAMENTOS}

A observação informal do cotidiano da interação no ambulatório permite inferir, com cautela, haver problemas na anamnese, porque os alunos têm dificuldade em pôr-se na perspectiva dos pacientes. O que faz sentido, pois é muito difícil, de pronto, entrar na lógica das narrativas dos pacientes. Não é trivial a constatação de que os pacientes têm apenas o termo da cultura popular para cada sintoma, enquanto, para os alunos/médicos, há no mínimo dois termos, o técnico e o popular. Concluímos, pensando na educação médica, que os alunos precisam de oportunidades de reflexão e esforço sistemático na arte de entrevistar. Precisam prestar atenção à recursividade, nos termos de Edel$\operatorname{man}^{2}$ (p. 150-1). Precisam exercitar-se nos recursos para pegar os ganchos e as deixas apresentados pelos pacientes e desdobrar-se na tarefa de sintonizar com a história das queixas para coletar o que lhes importa. Precisam de exercícios sistemáticos para focalizar o núcleo de interesse temático na narrativa dos pacientes no tempo recente e de domínio das técnicas para encadear e especialmente para dirigir a história dos pacientes. Com o domínio desses recursos e técnicas, as entrevistas vão evoluir, e eles vão alcançar resultados mais gratificantes com a anamnese.

Os alunos que têm dificuldade em interagir produtivamente com as expressões próprias da cultura dos pacientes serão os maiores beneficiários do que estamos propondo. Quando não entendem um termo ou uma expressão, os alunos, em vez de abandonarem esse termo ou expressão, tenderão a pedir elaboração e redescrição e, com isso, a salvar o tópico, que pode ser crucial para os pacientes. Por exemplo, serão levados a explorar e mapear o campo das possibilidades para entender o que os pacientes podem estar querendo dizer com tive uma dor no peito. $\mathrm{Ou}$ quando ouvem que o paciente passou por um amofinamento. Pas- 
sarão a reagir cooperativamente a quem diz que está com um abacaxi no coração, ou uma cachoeira no peito, ou um vazio na cabeça, ou que o tratamento foi sinistro.

Com essa estratégia, os alunos, enquanto interlocutores profissionais, irão incorporar a suas rotinas comunicativas uma atitude de escuta, para se impregnar do que o paciente constrói com dificuldade, pelo constrangimento diante do poder do médico e a assimetria no domínio da linguagem técnica e dos recursos para sintetizar o que sentem e vivenciam. Se os pacientes falassem alemão, a assimetria seria óbvia para ambos. No caso, nenhum dos dois parece perceber que falam línguas diferentes, apesar do uso das mesmas palavras (a linguagem técnica não é apenas um conjunto diverso de palavras - ela impõe significado diverso a palavras antigas). As diferenças aqui mencionadas são mais profundas do que normalmente se pensa e vão além de diferenças de classe social ou de escolaridade. Os alunos que se exercitarem sistematicamente na flexibilização das maneiras de perguntar disporão de um modelo de como dar conta, por escrito, da anamnese. Aprenderão a fazer sínteses contextualizadas, de modo a relatar, de forma concisa e coerente, o que viram e ouviram.

Os calouros continuarão a encantar-se com a nomenclatura técnica, com os epônimos, com os radicais gregos, mas controlarão o uso desses saberes na interação com pacientes que vêm de outra área disciplinar e de outro nível de formação e informação. Saberão temperar o léxico e abrir mão dos termos técnicos ao se comunicarem com os pacientes e nessa maleabilidade verbal e cognitiva entenderão parte substancial do que os pacientes dizem com outras linguagens, além da verbal - os gestos, o tom da voz, o olhar, a atitude. Saberão que são tradutores e que traduzir é uma atividade que exige uma sofisticação técnica apreciável, além de conhecimento do contexto de produção do discurso não basta o dicionário. Estarão aptos a captar os signos que, na comunicação, identificarão o que é primeiro plano ou figura, em oposição ao que é fundo; e a perceber que a anamnese não precisa se completar num só dia - ela pode se tornar um diálogo crescente, continuado.

Nesse contexto, cabe-nos propor estratégias e táticas para atenuar as dificuldades na comunicação entre os alunos e os pacientes: estratégias de entrevistas temáticas semiestruturadas, centradas em focos de interesse para os pacientes, em que as indicações e pistas dos pacientes são acolhidas e trabalhadas, mesmo que quebrem o fluxo básico da anamnese; esquemas maleáveis de redação de narrativas, em que a observação pessoal e o parecer pessoal sejam levados em conta; exercícios sistemáticos do ato de narrar experiência pessoal e de outras pessoas, com distinção entre o que se diz e o que se espera que o ouvinte faça, a partir do que se diz; exercícios sobre o modo de operar das condicionalidades contextuais, em que a palavra verbal é um dos ingredientes do que se está querendo comunicar; e por fim, consciência do papel da linguagem escrita, como documento e como guia para a tomada de decisões, que podem ser cruciais para a sobrevida do paciente. "a linguagem opera recursivamente para conectar o pensamento, a emoção, a memória e a experiência, o número de combinações discriminativas possíveis praticamente não tem limites" ${ }^{\prime 2}$. (p. 150)

Averdade que buscamos no exercício da medicina é, portanto,

um valor que deve ser trabalhado durante nossas interações pessoais e interpessoais. A riqueza dessas interações não é surpresa se considerarmos a "associatividade" e a "degeneratividade" das interações reentrantes em nosso cérebro². (p. 150-1)

\section{REFERÊNCIAS}

1. Moral RR. Relación médico-paciente: desafíos para la formación de profesionales de la salud. Interface (Botucatu) [on line] 2007; 11(23) [acesso em 16 dez. 2008]. 619-23. Disponível em htpp:www.scielo.br/scielo.php?script=sci_arttext\&pid=S141432832007000300015\&lng=en\&nrm=iso

2. Edelman GM. Second nature: Brain science and human knowledge. New Haven: Yale University Press; 2006.

3. Lightfoot D. The development of language: acquisition, change, and evolution. Oxford: Blackwell; 1999.

4. Sternberg RJ. Psicologia Cognitiva.. $4^{\circ}$ ed. Porto Alegre: Artmed; 2008.

5. Grice HP. Logic and conversation. In: Coles P, Morgan JL, (eds). Syntax and semantics III: Speech acts. New York: Academic Press; 1975. p. 41-58.

6. Raposo EP. Teoria da gramática: a faculdade da linguagem. Lisboa: Caminho; 1992.

7 Trask RL. 2004. Dicionário de linguagem e linguística. Trad. Rodolfo Ilari. São Paulo: Contexto; 2004.

8. Chomsky N. Language and problems of knowledge: The Managua lectures. Cambridge, Mass.: The MIT Press; 1988.

9. Bloom P. Overview: controversies in language acquisition. IN: Bloom P, editor. Language acquisition: core readings. Cambridge, MA: The MIT Press; 1994. p. 5-48.

10 Comrie B. Introduction. In: Comrie B, Matthews S, Po. linsky M, (eds). The atlas of languages: The origin and development of languages throughout the world. [New York]: Facts on File; 1996. p. 8-15.

11. Eysenck MW, Keane MT. Manual de Psicologia Cognitiva. $5^{\mathrm{a}}$ ed. Porto Alegre: Artmed; 2007. 
12. Aitchison J. Words in the mind: An introduction to the mental lexicon. 2nd. ed. Oxford: Blackwell; 1994.

13. Guindaste RM. 1996. O agramatismo: um estudo de caso em português [tese de doutoramento] Campinas: Unicamp. Instituto de Estudos da Linguagem. Programa de Pós-Graduação em Ciência, 1996 [acesso em 2008 Dez 16]. Disponível emhttp:/ /libdigi.unicamp.br/documentnt/?code=vtls0001011349

14. Collischonn G. O acento em português. In: Bisol L, editor. Introdução a estudos de fonologia do português brasileiro. 2a ed. rev. e ampl. Porto Alegre: EDIPUCRS; 1999. p. 125-58.

15. Ramos JM. Avaliação de dialetos brasileiros: o sotaque. Rev Est Ling. 1997; 6 (5): [acesso em 16 dez. 2008]. 103-25. Disponível em http://relin.letras.ufmg.br/revista/upload/05-Jania-Ramos.pdf

16. Ferreira CS, Mota JA, Freitas JMA, Andrade NM, Cardoso $\mathrm{SA}$, Rollemberg VL, et al. Atlas linguístico de Sergipe (cartas I-XI e 1-156). Salvador: UFBA; Fundação Estadual de Cultura de Sergipe; 1987.

17. Rossi N. Atlas prévio dos falares baianos. [Rio de Janeiro]: Instituto Nacional do Livro; Ministério de Educação e Cultura; 1963.

18. World Health Organization. History of the development of the ICD [acesso em $16 \mathrm{dez}$ 2008]. Disponível em:htpp://www.who.int/classifications/icd/en/HistoryOfICD.pdf

19. Coelho Filho JM. Relação médico-paciente: a essência perdida. Interface Comum Saúde Educ. [on line]. 2007. 11(23) [acesso em 16 dez. 2008] 631-3. Disponível em http: / / www.scielo.br/scielo.php?script=sci_arttext\&pid=S1414-32832007000300018\&lng=en\&nrm=iso

20. Rios IC. Ser e fazer diferente... É possível provocar o desejo? Interface (Botucatu) 2007 Dez; 11 (23): 628-30 [acesso em 2008 Dez 16]. Disponível em http://www.scielo.br/scielo.php?script=sci_arttext\&pid=S1414-32832007000300017\&lng=en\&nrm=iso

21. Roberts JM, Forman ML. Riddles: Expressive models of interrogation. In: Jumpers JJ, Hymes D, (eds). Directions in Sociolinguistics: the ethnography of communication .Oxford: Basil Blackwell; 1972. p. 180-209.

22 Tannen D. That's not what I meant! London: J.M. Dent \& Sons; 1986.

\section{CONTRIBUIÇÃO DOS AUTORES}

Os autores Sebastião José Votre, Maria Carlota Rosa e Nelson de Albuquerque Souza e Silva participaram da concepção inicial do estudo, do desenho, análise, interpretação dos dados e da redação final do texto. Diana Maul de Carvalho participou igualmente do desenho, da análise, interpretação dos dados e da redação final do texto.

\section{CONFLITO DE INTERESSES}

Declarou não haver.

\section{ENDEREÇO PARA CORRESPONDÊNCIA}

Sebastião Josué Votre

Rua Mário Pederneiras, 4, ap.to 204

Humaitá Rio de Janeiro

CEP 22261020 RJ

E-mail: sebastianovotre@yahoo.com 